\title{
SOPHIA
}

PEER REVIEW JOURNAL

VISUAL SPACES OF CHANGE: UNVEILING THE PUBLICNESS OF URBAN SPACE

THROUGH PHOTOGRAPHY AND IMAGE

ISSN: 2183-8976 [PRINT] 2183-9468 [ONLINE]

Volume 4, Issue 1| Publication year: 2019

DOI 10.24840/2183-8976_2019-0004_0001_02

(c) SCOPIO EDITIONS

HOMEPAGE: HTTPS://WWW.SOPHIAJOURNAL.NET

\section{ABOUT THE 5TH INTERNATIONAL CONFERENCE ON THE SURFACE}

Written by Pedro Gadanho and Pedro Leão Neto

The 5th International Conference On the Surface: Photography on Architecture - Visual Spaces of Change: Unveiling the Publicness of Urban Space through Photography and Image, which took place on the 31st of May 2019 on occasion of MAAT's Fiction and Fabrication exhibition offered a forum for an interdisciplinary debate on photography and architecture, with a strong editorial component devoted to the publication of original works and ideas at the intersection of these two fields.

Aiming to promote the awareness and reflection upon Architecture and Art, namely documentary photography in regard to its conception as an instrument to question the universes of Architecture, City and Territory, the theme chosen for this edition of On the Surface focused on the contemporary transformations of the public space: "Visual Spaces of Change: unveiling the publicness of urban space". Proposing to debate and explore the potential of Image and Photography as resourceful tools to research and to reflect upon and render visible the emergence of new collective experiences in the social space, the focus was on Documentary and Artistic Photography for addressing crosscutting issues that are shaping contemporary changes in cosmopolitan territories. This conference wanted in this way to contribute for greater social interaction among artistic and cultural institutions and academia, extending the action of museums, universities and art venues beyond their traditionally circumscribed spaces of action, stimulating the agents and institutions involved to be more active and open to debate in their approaches to public space. The intention was to render visible aspects of urban change, as well as how architectures, places and spaces are used and lived, crossing and shifting traditional boundaries for expanding the capacity of institutions to participate in the public domain. In this sense, we aim to contribute for critically thinking architecture as an integrative field of knowledge with historical, cultural, social, economic and political dimensions, and explore photography as a dynamic process of discovery, documentation and reflection that incorporates interpretive, artistic and even fictional aspects of these multiple dimensions. 
On the Surface 2019 challenged authors and researchers from the fields of photography and architecture to discuss and use image and photography to better understand the city as a living organism, a rich multifaceted space characterized by a variety of experiences and programs, which are a reflection of the knowledge, beliefs, values and customs that characterize different societies. Thus, a central objective of the conference was to discuss in what way image and photography can be used to unveil how architecture expresses the cultural values and identity of our cities, being these critical research instruments for understanding and perceiving architecture in meaningful ways, as well as for understanding the past in order to better grasp the transformations that are increasingly influencing our social practices and place experiences, affecting the modes of citizen participation and cultural interaction. By overlapping and crisscrossing the disciplinary boundaries of Image, Art and Architecture, the borders of these disciplinary fields are challenged for critically thinking through contemporary changes occurring in between physical and virtual dimensions of everyday life. Through the realization of these debates, it was intended to contribute to the creation of a space of exploration, discussion and reflection towards new ideas and research paths about the use of photography as an instrument of visual research and communication, as well as about architecture and the public space, with a focus on emerging dynamics of urban transformation.

Lastly it is important to refer the significant connection of this conference to the project Visual Spaces of Change that the Faculty of Architecture of the University of Porto (FAUP) is coordinating, which integrates a significant component of Contemporary Photography in its research, together with the participation of other national and international academic bodies and research institutions that are involved. In fact, by bringing some of the themes of the VSC research project to this 5th edition of On the Surface: Photography on Architecture, we aim to contribute for opening academia to society, fostering collaboration among a wide range of cultural and artistic institutions towards common interests and goals. Intertwining the research group CCRE-CEAU-FAUP and Cityscopio Cultural Association, scopio Editions will be again the official publisher of this conference.

Thus this 4th number of Sophia[1], Visual Spaces of Change: Unveiling the Publicness of Urban Space through Photography and Image is dedicated to this International Conference On the Surface: Photography and Architecture - Visual Spaces of Change: Unveiling the Publicness of Urban Space, publishing the papers based on the works that were presented at the conference.

These papers constitute a significant example of investigation on how contemporary photography can be explored as a meaningful instrument of research about contemporary processes of urban change, producing visual synthesis about how architectures, places and spaces are used and lived, rendering visible aspects which are difficult to perceive without the purposeful use of image and photography. This means, besides other things, to inquire and study the possibilities offered by photography in various dimensions, oscillating between reality, poetry and utopia, creatively introducing new links between realistic representations, fictional worlds and symbolic meanings, articulated in conceptual discourses and visual narratives that are communicated through the specific grammar and syntax of photographic image. 
The conference was organized by the Center of Communication and Spatial Representation (CCRE), integrated in R\&D Center of the Architecture School of the University of Porto (FAUP), in partnership with the Museum of Art, Architecture and Technology (MAAT) and scopio Editions.

This article is a result of the project POCl-01-0145-FEDER-030605 - PTDC/ART-OUT/30605/2017 supported by Competitiveness and Internationalisation Operational Programme (POCI), under the PORTUGAL 2020 Partnership Agreement, through the European Regional Development Fund (ERDF) and through national funds by the FCT - Fundação para a Ciência e a Tecnologia. 